\title{
The Added Value of a New, Innovative Travel Service: Insights from the UbiGo Field Operational Test in Gothenburg, Sweden
}

\author{
Jana Sochor*, Helena Strömberg, and I.C. MariAnne Karlsson \\ Chalmers University of Technology, Division Design \& Human Factors, \\ SE-412 96 Gothenburg, Sweden \\ e-mail \{jana.sochor;helena.stromberg;mak\}@ chalmers.se
}

\begin{abstract}
The aim of this paper is to introduce the UbiGo transport broker service developed in Gothenburg, Sweden, and to discuss insights from the sixmonth field operational test regarding incentives for users adopting new travel services as well as perceived added value. Results are presented from participant questionnaires, interviews, and travel diaries. Findings suggest that potential early users are initially incentivized by curiosity, but that this must be transformed into practical incentives such as convenience and economic advantage if the users are to continue using the service. Customers also found added value in the "transportation smorgasbord" concept, 24-hour customer support, new types of subscriptions and tickets, and having everything in their smartphone, but wished for more personalized decision support and feedback. Concern for the environment functioned more as a bonus than as an incentive, meaning that the environmentally friendly choice must also be the practical choice in order to promote sustainability.
\end{abstract}

Keywords: field operational test, multimodal travel, seamless travel, travel service, incentive, added value

\section{Introduction}

On the one hand urban mobility is vital for the functioning of cities, on the other hand it causes problems in terms of e.g. emissions and noise. A large number of projects has been implemented to bring about changes regarding transportation of people. In addition to economic and legal measures, commuters have for instance been the targets of information and education campaigns to raise awareness and change attitudes towards mode choice, e.g. [1], [2], [3], [4]. Other projects have tried to stimulate and motivate change through competitions or handing out free public transportation passes, e.g. [5], [6], [7]. Considerable efforts have also been made to increase the attractiveness of public transport, for instance by introducing vehicles with improved designs and traveler information, e.g. [8], [9], [10], [11]. To alter people's travel habits is difficult, however, and the progress, albeit positive, is too limited to meet the challenges ahead; a more innovative solution is needed to bring about more radical changes.

In order to reduce traffic by maintaining or increasing the level of mobility for citizens (and goods), one challenge is how to use the current infrastructure more efficiently and to encourage multimodality. Technological approaches discussed are 
smartphone and web applications facilitating the processes of booking, ticketing, and organization of city logistics [12].

The Go:Smart project is an attempt to create better conditions for sustainable travel by demonstrating how new business models and partnerships can reduce the need for private car ownership in favor of seamlessness, multimodality, and use of information technology. The vision was an integrated mobility service for end consumers providing a seamless, multimodal journey experience including public transport interlinked with car and bike-sharing. The underlying assumptions behind the project were:

- Changes in travel behavior face deterring and incentivizing factors. Deterring factors include different efforts such as changing habits, a need for learning, economic investments, etc. Incentivizing factors are anticipated and perceived benefits, including economic gains, increased status, etc.;

- Incentives can be intrinsic as well as extrinsic [13] in terms of punishments or rewards. Providing feedback in terms of some kind of reward can have a positive effect on encouraging and maintaining a desired behavior, cf. [14];

- Current shifts in individuals' attitudes and values, cf. [14], in a more environmentally conscious direction, and the trends towards joint/shared ownership or no ownership at all (including car- and bikesharing) open up new possibilities for new types of travel offers.

Identified preconditions were that the desired changes cannot be brought about by the development of a single transport mode or by focusing solely on a shift from fossil-fuelled, private cars to public transportation, but by the integration of different transportation services, public and private, i.e. "collective transport"; and furthermore that the developments in Information and Communication Technology (ICT) as well as the dissemination of mobile ICT has made it increasingly possible to create and test new and smarter offers.

The Go:Smart project has involved the development and Field Operational Test (FOT) of an innovative transport broker service, named UbiGo, for sustainable transportation of people in urban environments. The service has attempted to bridge the gap between private and public transportation by taking on the role of a commercial actor, "a broker of everyday travel", offering customized transport services to fit the individual traveler's needs and requirements. More than 190 individuals became paying customers for six months (November 2013 - April 2014).

This paper presents early results from the FOT regarding which values - both added values to the individual customer and wider, social values - can be created or fostered by a new, innovative, ICT-based approach to mobility services. Questions posed were: What incentivizes people to become and remain customers? What added values - expected and unexpected - were created by the service concept?; by the ICTbased platform? What added values were expected but not realized?

\section{The UbiGo Transport Broker Service}

The UbiGo service offered its users one-stop access to a range of travel services through a web-interface adapted to smartphones (subsequently referred to as the app). It was built up as a monthly subscription service where a household (which may be 
comprised of multiple persons; adults and children) decided their desired combination of, and amount of credit for: public transportation, carsharing, car rentals, bikesharing, and taxi service. Credit could be topped up or rolled over. The subscription could also be modified on a monthly basis.

To access their travel services, the UbiGo traveler logged into the app via a Google- or Facebook-login, where they could activate tickets/trips, make/check bookings, and access already activated tickets (e.g. for validation purposes). The app allowed them to check their balance, bonus, and trip history, and get support (FAQ/customer service). Each participant received a smartcard, used e.g. to check out a bicycle or unlock a booked car, but also charged with extra credit for the public transportation system in case there was any problem using the UbiGo service. UbiGo included a customer service line open 24 hours per day.

\section{Method}

The original participant group consisted of 83 customer subscriptions covering 195 persons: 173 adults and 22 children $(<18$ years). A total of 21 private vehicles were deliberately not used during the FOT (from November 1, 2013 to April 30, 2014).

To evaluate the participants' experiences and travel behaviors, data was collected via a mixed-methods approach including questionnaires, interviews, focus groups, and travel diaries, as well as workshops and logging of customer service issues. The "before", "during" and "after" questionnaires were sent out to all participants (optional for children) and completed by 164, 161 and 160 participants respectively (with 151 adults completing all three). Ex-post interviews were carried out with 14 individual participants and with three households. Three ex-post focus groups were also conducted. One-week travel diaries were completed by 40 ("before") and 36 (“during") participants, respectively.

Statistical analyses of the questionnaire data were performed with the software IBM SPSS. Recordings of all interviews and focus groups were transcribed in full for analysis. All trips in the "before" travel diaries were summarized and the participants" choices of travel mode were compared with the averages for Gothenburg.

\section{Results}

\subsection{Socio-demographics and Ex-ante Travel Behavior}

From the "before" questionnaire (164 responses), the participant group had an average age of 38 years and consisted of approximately $50 \%$ women. The majority was employed (80\%) and had a driver's license (88\%) although only $41 \%$ stated that they have daily personal access to a car. The majority owned a bicycle (81\%) and had a public transportation card (88\%), but few were bikesharing members (19\%).

Most lived in apartments $(80 \%)$ and there was a mix of household types (mostly multiple adults with/without children) and income levels. Also, a slight majority did not own a car (52\%) and the majority was not a carsharing member (69\%). 
A large majority of participants used the internet and apps on computers, tablets, and smartphones on a daily basis $(88-91 \%$ in all cases). (Note that one needs a smartphone in order to run the UbiGo app.)

An initial analysis of the "before" travel diaries (846 trips from 24 women and 16 men) revealed that the participants differed somewhat from the average Gothenburg resident [15]. In terms of car use, the participant group was most similar to the average person living in Central Gothenburg (27\% versus $24 \%$, respectively). However, their use of alternative modes differed somewhat in that more participants used public transportation (34\% versus $26 \%$, respectively) and fewer walked $(24 \%$ versus $39 \%$, respectively).

\subsection{Incentives and Added Value}

When asking participants about their primary reason for joining UbiGo ("before" questionnaire), curiosity was by far the strongest reason, with $63 \%$ claiming this as their primary reason. In fact, all other reasons such as conveniencelflexibility, economy, environment, family member, gaining access to cars, and/or test living without a privately owned car significantly lagged behind curiosity. According to the "during" questionnaire results, curiosity lost its dominant position (from 63\% to $25 \%$ ), while convenience/flexibility (22\%) and economy (14\%) increased as reasons to continue as a customer. Results from the "after" questionnaire revealed that convenience/flexibility became the dominant reason $(30 \%)$, followed by curiosity $(21 \%)$ and economy (14\%) (see Figure 1).

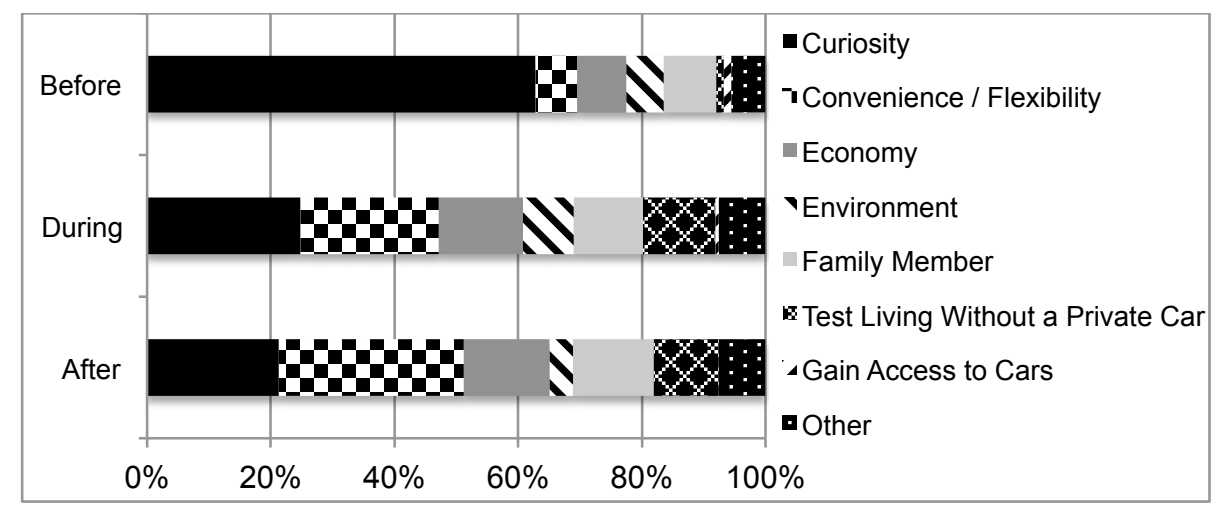

Fig. 1. Primary incentive of the participant group over time.

Besides the practical aspects of convenience/flexibility and economy, interview results revealed several other appreciated features:

- The "transportation smorgasbord" concept, with the majority of one's travel needs offered in one package. Here, environment comes into play, as participants were initially attracted to the concept of UbiGo and felt that it was an added bonus if it meant potentially more environmentally friendly travel as well. 
- The type of subscription, where many people (not even living under the same roof) could be included in one subscription with one monthly invoice. Not only could customers get an overview of their monthly transportation expenditures, they could easily "support" other relatives (e.g. grown children or aging parents) as well.

- The daily public transportation ticket, reasonably priced, based on a more generous zone system, and activated once rather than using the tap-in/out system. It was also easy to upgrade to additional zones on a particular day.

- A smartphone-based system, illustrated by the participant comment: "I can forget my public transportation card, but I cannot forget my phone".

- 24-hour customer support with only one telephone number. Rather than different numbers for UbiGo and each subservice, all customer support was handled via one number, which could easily be found in the app.

Although not necessarily a feature that created added value (it was almost never utilized during the FOT), the "improved" travel guarantee, where UbiGo promised to deal with the expenditure and administration, is likely a feature that cannot be eliminated as it creates a sense of security. Surprisingly, the feature that could potentially be eliminated, or at least modified, is the bonus system for "eco-friendly" travel, where the UbiGo traveler accumulated points (based on reduced $\mathrm{kg}$ of $\mathrm{CO}_{2}$ compared to making the same trip by private car) that could be exchanged for other goods and services. Most did not exploit the rewards offered by the bonus system, and those who did tended to do it at the very end of the FOT. Participants felt that if there was a bonus system, it should be tied to the service itself by giving internal, transportation-related rewards, rather than external rewards.

One feature that was lacking, but that customers wished for and that would likely create added value, is personalized decision support and feedback. Customers wanted the system to suggest alternatives based on various factors such as time, distance, cost, $\mathrm{CO}_{2}$, etc., and they wanted the system to give them feedback about their travel behavior. Due to non-transparent pricing schemes, customers also wanted the system to help compare alternatives, e.g. the price of renting versus carsharing versus taxi.

\section{Discussion and Conclusions}

The UbiGo service was designed and implemented with the intention to contribute to a more sustainable transportation of people. The results demonstrate the potential and importance of ICT as a mediator in developing an innovative and attractive mobility solution such as UbiGo.

Although, as with any new service, there are still improvements to be made, the UbiGo broker service has been very well received and $79 \%$ of the participants in the FOT stated that they definitely wanted to continue using the service while $18 \%$ stated probably (given certain preconditions). Indeed, in the "after" questionnaire, people stated that they used private car less and public transportation, walking, and cycling more often than before, and they also felt more negative towards private car and more positive towards public transportation, etc., than before. When asked how their travel behavior had changed, $35.6 \%$ reported no change, while $42.5 \%$ reported changes in mode choice, $34.4 \%$ in pre-trip travel planning, $21.3 \%$ in destinations, trip duration, and trip chaining, and $20.6 \%$ in their amount of exercise. (Note that the type of 
change is not specified, e.g. more or less.) Of those who reported behavioral changes, only $2.9 \%$ were dissatisfied with the changes and $17 \%$ felt that the changes would not last, in particular if/when the service stops.

This initial analysis of the FOT shows that it is vital to generate interest and excitement about new transportation schemes. This is the primary reason that participants were attracted to the project or were willing to become customers in this FOT, with all that it entails. The results support also the notion that the innovation (here in terms of a practice) must offer some added value or relative advantage, cf. [16], to be adopted, i.e. the service must appeal to the users on a practical level and facilitate their daily travel. When it has not been curiosity motivating people, it has been convenience and economy, and it is these practicalities that will keep the users incentivized to continue using the service after the novelty and curiosity fade.

The results suggest furthermore that relative advantages cannot by replaced by rewards. In fact, the reward system appears to have played a minor role (if any) in the adoption of the new service. Moreover, although the environment is of concern for many, it has not proven to be a primary incentive (despite the participant group already having relatively more sustainable travel behavior based on the initial analysis of the "before" travel diaries). In this specific case, it is possible that informational feedback, cf. [17], on how "green" your travel patterns are could be just as, or even more, important to users. However, the eco-friendliness is not enough to attract a sufficient number of customers and a pro-environmental attitude will not suffice as an incentive for change, at least not for majority of travelers. If the environmental impact of transportation is to be reduced, then reductions must be achieved by making more sustainable travel behavior the practical choice, rather than the idealistic choice.

\section{References}

1. Batterbury, S.: Environmental activism and social networks: campaigning for bicycles and alternative transport in West London. Ann. Am. Acad. Polit. SS. 590, 150-169 (2003)

2. Brög, W., Erl, E., Mense, N.: Individualised marketing. Changing travel behavior for a better environment. OECD workshop on Environmentally Sustainable Transport, Berlin (2002).

3. Henry, G.T., Gordon, C.S.: Driving less for better air: Impacts for a public information campaign. J Policy Anal. Manag. 22(1), 45-63 (2002)

4. Midgley, P.: Bicycle-sharing schemes: Enhancing Sustainable Mobility in Urban Areas. Background Paper, U.N. Dept. of Economic and Social Affairs, CDS 19/2011/BP8 (2011)

5. Fujii, S., Kitamura, R.: What does a one-month free bus ticket do to habitual drivers? An experimental analysis of habit and attitude change. Transportation, 30, 81-95 (2003)

6. Root, A.: Can travel vouchers encourage more sustainable travel? Transport Policy. 8(2), 107-114 (2001)

7. Thørgersen, J., Møller, B.: Breaking car use habits: The effects of a free one-month travel card. Transportation. 35(3), 329-345 (2008)

8. Currie, G., Wallis, I.: Effective ways to grow urban bus markets - a synthesis of evidence. J of Transport Geogr. 16(6), 419-429 (2008)

9. Dziekan, K., Kottenhoff, K.: Dynamic at-stop real-time information displays for public transport: effects on customers. Transportation Res. A-Pol. 41(6), 489-501 (2007)

10. Monzon, A., Hernandez, S., Cascajo, R.: Quality of bus services performance: benefits of real-time information systems. Transportation and Telecommun. 14(2), 155-166 (2013) 
International Conference on Mobility and Smart Cities, Rome, October 27-28, 2014

11. Skoglund, T., Karlsson, M.: Appreciated but with a fading grace of novelty. Traveller's assessment of, usage and behavioural change given access to a co-modal travel planner. Procedia - Soc. Behav. Sci. 932-940 (2012)

12. Smart Cities and Communities, http://eu-smartcities.eu/mobility_transport

13. Frey, B.S.: Motivation a limit to pricing. J Econ. Psychol. 14, 635-664 (1993)

14. Fishbein, M., Ajzen, I. Belief, attitude, intention and behavior: An introduction to theory and research. Addison-Wesley, Reading, MA (1975)

15. Swedish Transportation Administration: Resvaneundersökning 2011 Västsvenska Paketet. Technical Report, Swedish Transportation Administration (2011)

16. Rogers, E.M.: Diffusion of Innovations, 5E. Simon and Schuster, New York (2003)

17. Dwyer, W.O., Leeming, F.C., Cobern, M.K., Porter, B.E., Jackson, J.M.: Critical review of behavioral interventions to preserve the environment: Research since 1980. Environ. Behav. 25, 275-321 (1993) 